\title{
Outbreak of Salmonella enterica Goldcoast infection associated with whelk consumption, England, June to October 2013
}

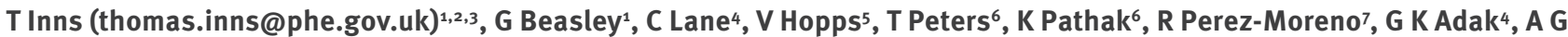

Shankar ${ }^{1}$, on behalf of the Outbreak Control Team

1. Anglia and Essex Centre, Public Health England, United Kingdom

2. Field Epidemiology Training Programme, Public Health England, United Kingdom

3. European Programme for Intervention Epidemiology Training (EPIET), European Centre for Disease Prevention and Control (ECDC), Stockholm, Sweden

4. Centre for Infectious Disease Surveillance and Control, Public Health England, United Kingdom

5. Kings Lynn \& West Norfolk Borough Council, United Kingdom

6. Microbiology Services, Public Health England, United Kingdom

7. Incidents Unit, Food Standards Agency, United Kingdom

Citation style for this article:

Inns T, Beasley G, Lane C, Hopps V, Peters T, Pathak K, Perez-Moreno R, Adak GK, Shankar AG, on behalf of the Outbreak Control Team. Outbreak of Salmonella enterica Goldcoast infection associated with whelk consumption, England, June to October 2013. Euro Surveill. 2013;18(49):pii=20654. Available online: http:// www.eurosurveillance.org/ViewArticle.aspx?Articleld=20654

Article submitted on 22 November 2013 / published on 05 December 2013

An increase in the number of cases of Salmonella enterica serotype Goldcoast infection was observed in England during September 2013. A total of 38 cases were reported, with symptom onset dates between 21 June and 6 October 2013. Epidemiological, environmental, microbiological and food chain evidence all support the conclusion that this outbreak was associated with eating whelks processed by the same factory. Whelks are a novel vehicle of Salmonella infection and should be considered when investigating future outbreaks.

\section{Identification of outbreak}

During September 2013, 17 laboratory-confirmed cases of Salmonella enterica serotype Goldcoast infection with gastroenteritis were reported in England. This number was greater than the annually expected number: in 2012, eight cases were reported in England, in 2011, five were reported and in 2010, 13 were reported. Public Health England initiated an investigation on 12 September 2013 in order to identify the source of the outbreak and enable suitable control measures to be put in place to prevent further cases. The last case, with symptom onset in October, was reported on 12 November 2013, bringing the number of reported cases to 38 . The cases' ages ranged between six months and 83 years (median: 64 years); two were aged under 16 years. Of the 38 cases, 25 were male. All cases were resident in England, predominantly in the east of the country (Figure 1).

As the incidence of this serotype is expected to be low, we looked at reports in the previous three months. Symptom onset dates ranged from 21 June 2013 (week 25) to 6 October 2013 (week 41) (Figure 2). Before this, the last case was reported in January 2013. Of the 38

\section{FIGURE 1}

Place of residence of cases of Salmonella enterica Goldcoast infection, England, weeks 25-41 2013 (n=38)

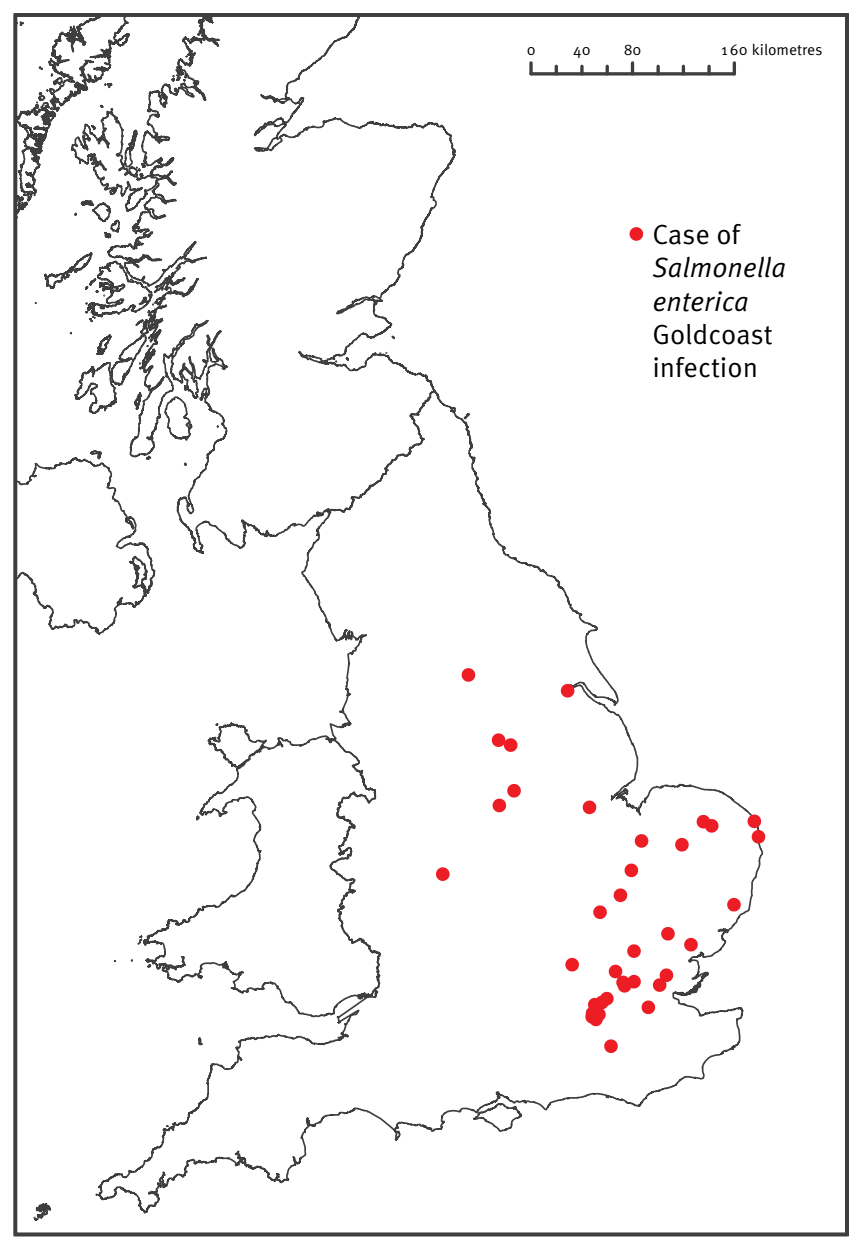

a Week 25 started on 17 June 2013. 


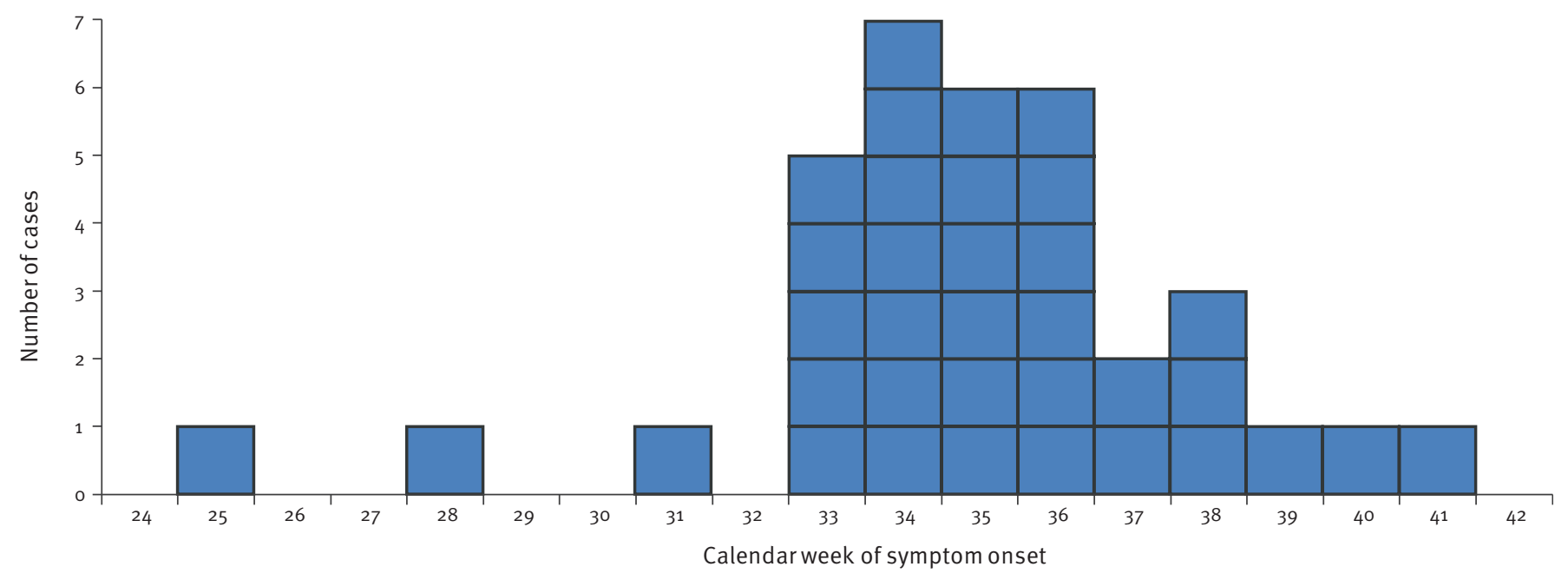

a Week 24 started on 10 June 2013.

${ }^{\mathrm{b}}$ Onset dates were unobtainable for three cases.

cases, 10 were hospitalised, of whom four were admitted to intensive care. The median duration of illness was 13 days (range: 4-21); seven cases were symptomatic at the time they were first asked about their symptoms. Of the 35 cases for whom data on symptoms were available, all had diarrhoea; other symptoms included nausea $(n=22)$, abdominal pain $(n=22)$, fever $(n=17)$, vomiting $(n=15)$, headache $(n=15)$ and blood in stools $(n=3)$.

\section{Epidemiological investigation}

Outbreak cases were defined as persons resident in England diagnosed with Salmonella Goldcoast infection by the Salmonella Reference Service (Public Health England, London) after 1 June 2013. All laboratories in England and Wales send all Salmonella samples to this reference service.

To generate a hypothesis as to the source of this outbreak, we undertook detailed telephone interviews of the first 10 cases, with a trawling questionnaire. The questionnaire included demographics, clinical details, information on travel and contact with symptomatic persons, events attended and a detailed food history (including a general seafood question) for the week before symptom onset, including venues eaten at, and types and origin of foods eaten at home. Of the three cases with the earliest symptom onset dates, two reported having eaten whelks. Whelk consumption was reported by five of the 10 cases interviewed; this was much higher than the expected level of whelk consumption (for gastroenteritis questionnaires routinely completed in the east of England, eating whelks is reported by less than $1 \%$ of cases). Therefore, our primary hypothesis was that illness was associated with eating whelks (Buccinum undatum).
We then undertook an unmatched case-control study to test the hypothesis that whelk consumption was associated with Salmonella Goldcoast infection in England in 2013. Cases were excluded from the study if they were aged under 16 years (for logistic reasons), had travelled outside the United Kingdom (UK) in the five days before onset of symptoms, had had close contact with other individuals with gastroenteritis in the five days before onset, were asymptomatic or had already been interviewed with the trawling questionnaire. Controls were recruited through a systematic digit dialling process, using the home telephone number of cases to generate telephone numbers of people who were then contacted. We initially aimed to recruit two controls per case, but subsequently reduced this due to the strength of association observed. Information was collected from participants using a pre-tested questionnaire that was administered over the telephone by trained investigators. The questionnaire included questions on the following: demographics, clinical details, travel history, contact with persons with diarrhoea, events attended and foods eaten, including location of purchase, in the week before symptom onset. Foods in addition to whelks that were eaten by at least eight cases in the trawling questionnaire were included in the case-control study.

Data from the questionnaire were entered into a database using EpiData 3.1. Data were checked and analysed using Stata v12.1. The association between illness and each variable was estimated using odds ratios (ORs) and 95\% confidence intervals (Cls). Data were subjected to univariable analysis and stratification to test for effect modification and confounding together with multivariable analysis using logistic regression. 
Univariable and multivariable associations between food exposure and Salmonella enterica Goldcoast infection, England, weeks $25-41^{\text {a }} 2013$

\begin{tabular}{|c|c|c|c|c|c|c|c|c|}
\hline \multirow{2}{*}{ Food exposure } & \multirow{2}{*}{$\begin{array}{c}\text { Case } \\
\mathrm{n}=20^{\mathrm{b}}\end{array}$} & \multirow{2}{*}{$\begin{array}{c}\begin{array}{c}\text { Control } \\
n=27\end{array} \\
\text { Number exposed }\end{array}$} & \multicolumn{3}{|c|}{ Univariable analysis } & \multicolumn{3}{|c|}{ Multivariable analysis } \\
\hline & & & OR & $95 \% \mathrm{Cl}$ & p value & OR & $95 \% \mathrm{Cl}$ & $p$ value \\
\hline Whelks & 16 & 1 & 104 & $9 \cdot 54-4,517$ & $<0.001$ & 109 & $7 \cdot 7-1,539$ & 0.001 \\
\hline Cockles & 5 & 0 & $\mathrm{NC}$ & $2.1-\infty$ & 0.010 & - & - & - \\
\hline Lettuce & 10 & 22 & 0.2 & $0.05-0.99$ & 0.030 & - & - & - \\
\hline Fish & 7 & 18 & 0.3 & $0.07-1.06$ & 0.420 & - & - & - \\
\hline Peppers & 5 & 15 & 0.3 & $0.06-1.09$ & 0.044 & - & - & - \\
\hline
\end{tabular}

$\mathrm{Cl}$ : confidence interval; NC: Not calculable; OR: odds ratio.

a Week 25 started on 17 June 2013.

b Two of the 22 cases eligible for inclusion in the case-control study chose not to participate.

' $p$ value derived using Fisher's Exact test.

Statistically significant exposures at the alpha $=0.05$ level were added to the multivariable model. These were retained if they significantly improved the model, as assessed using a likelihood ratio test.

\section{Food chain investigation}

Foods identified in the trawling questionnaire and case-control study were investigated by environmental health officers and the Food Standards Agency. From each point of sale, distributers and suppliers were traced. Links between suppliers were mapped to produce a food chain diagram.

Food and environmental samples were taken using appropriate media. Samples were tested for presence of Escherichia coli and Salmonella. Presumptive Salmonella isolates were screened using a real-time polymerase chain reaction (PCR) assay for identification of the most common subspecies of $S$. enterica $[1,2]$. Serum agglutination tests, using KauffmannWhite classification [3], confirmed the presence of S. enterica serovar Goldcoast $(6,8: \mathrm{r}: \mathrm{l}, \mathrm{w})$.

\section{Analytical epidemiology}

In total, 22 cases were eligible for the case-control study: of these, 20 cases were included (two cases declined to participate). A total of 27 controls were included. In a univariable analysis, cases were significantly more likely than controls to have consumed whelks, cockles, lettuce, fish and peppers (Table). No effect modification was detected. In the final multivariable model, when adjusted for sex, cases were significantly more likely to have consumed whelks (OR: 109; 95\% Cl: 7.7-1,539).

\section{Food and environmental microbiology}

Whelk consumption was reported by 24 of the 38 cases and one of the 27 controls; venues that these cases reported purchasing whelks from were investigated by environmental health officers. A summary of the food chain inferred from these investigations is shown in Figure 3. The supplier could be traced for whelks eaten by 20 cases: all were traced back to whelks processed by the same factory (Factory $X$ ). The whelks eaten by the control were not supplied by Factory $X$.

Factory $X$ is a seafood factory in England; in 2012 it processed $639,049 \mathrm{~kg}$ of whelk meat. Whelks are processed by cooking in a pressure cooker. Their shells are then crushed and removed before the meat is cooled in a water bath. A small proportion is then sold fresh, with the majority of cooked whelks being flash frozen before sale. Over $90 \%$ of cooked whelks from Factory $X$ are shipped to a single non-European Union country for further processing and consumption; the remainder are sold in the UK.

A total of 11 samples of whelks that had been processed at Factory $X$ were taken at the point of sale from four outlets; two of the samples were positive for Salmonella Goldcoast. Seven processed and two raw whelk samples were taken from Factory $X$ : none were positive for Salmonella Goldcoast. We tested 33 swabs or water samples from whelk-processing machinery at Factory X: six tested positive for Salmonella Goldcoast.

\section{Control measures}

Following initial descriptive epidemiology and food tracing investigations, Factory $\mathrm{X}$ was visited by environmental health officers on 20 September 2013. Cooking temperatures could not be verified and the factory agreed not to produce ready-to-eat whelks until further notice. During a subsequent inspection on 23 September, inadequate product temperatures were recorded immediately following cooking and therefore the whelks processed on that day and stored frozen on the premises were kept on the site. Due to the problems identified in the processing of whelks, the factory 


\section{FIGURE 3}

Results of food chain investigations, Salmonella enterica Goldcoast infection, England, weeks 25-41 2013 ( $\mathrm{n}=20)$

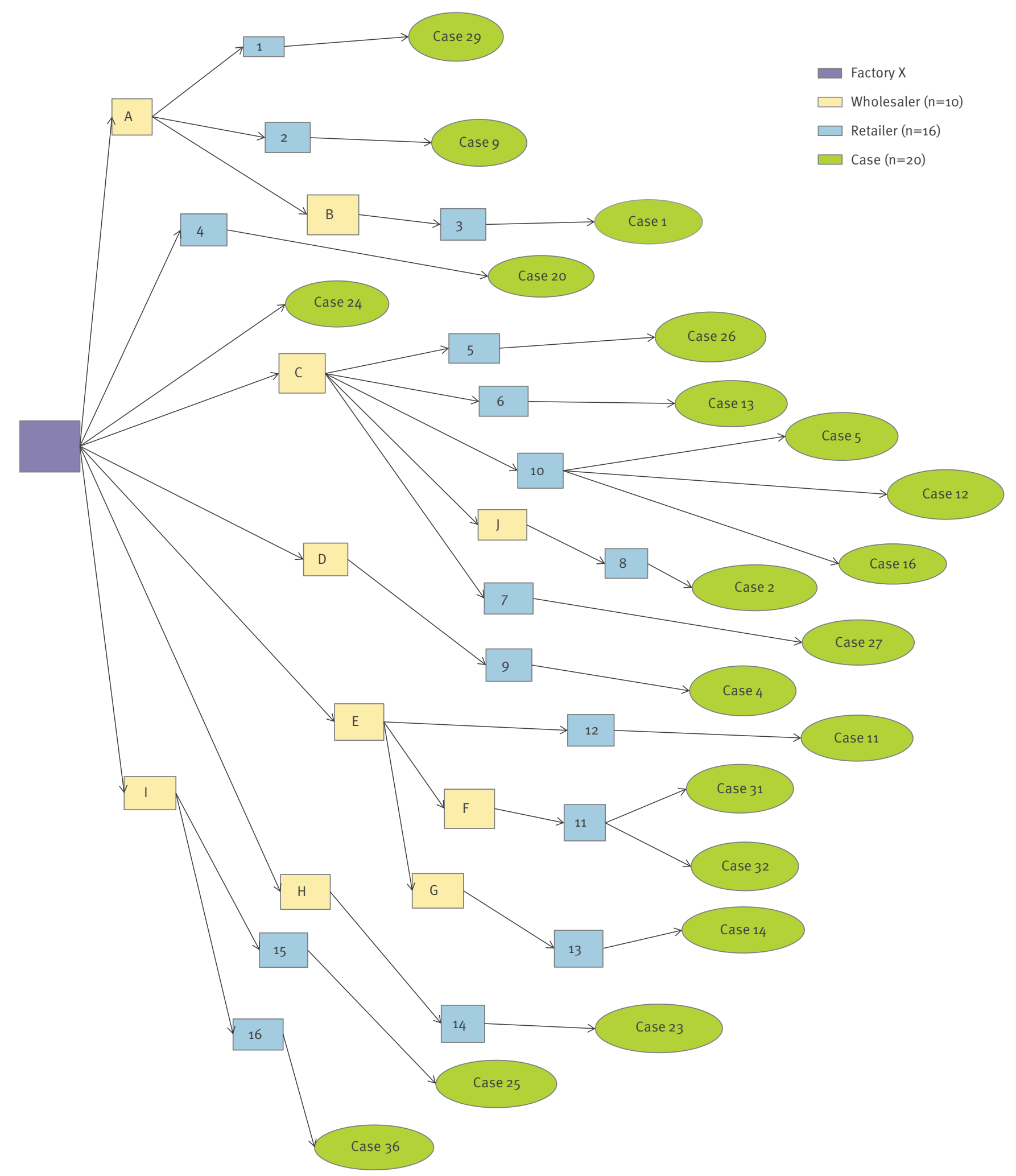

a Week 25 started on 17 June 2013. 
instigated a product recall on 23 September 2013. The effectiveness of this recall was monitored by the Food Standards Agency and associated local authorities. The Foods Standards Agency informed the competent authorities in the country that this product is exported to: to date, no cases have been reported.

\section{Discussion}

We present epidemiological, environmental, microbiological and food chain evidence, which all support the conclusion that this outbreak of Salmonella Goldcoast infection was associated with consumption of whelks processed by Factory X. Salmonella Goldcoast outbreaks have previously been associated with pork products (salami [4], pork cheese (cooked pig organs stuffed in a pig stomach) [5], French paté [6] and raw fermented sausage [7]), watercress [8] and hard cheese [9]. Whelks have previously been associated with toxin-based food poisoning [10] but to our knowledge, this outbreak is the first known report of bacterial food poisoning associated with whelk consumption.

Regarding the mechanism of Salmonella Goldcoast contamination, microbiological evidence suggests that production equipment in contact with cooked whelks was contaminated with Salmonella Goldcoast for a number of weeks, despite the use of a sanitiser and the cooked whelks passing through a highly saline bath. Salmonella Senftenberg has previously been observed to survive in high salinity environments [11]: it may be that Salmonella Goldcoast shares this characteristic.

There was limited evidence that could indicate the original source of the Salmonella Goldcoast contamination. One of the environmental samples that tested positive for Salmonella Goldcoast was a swab of the conveyer belt used to transport raw whelks to the cooker, indicating that it was present on at least some whelks before entering the factory. Whelks are not filter feeders, and it is unclear whether they ingested the bacteria or the pathogens were in water that contaminated the shells. On the basis of the epidemiological evidence, we hypothesise that contaminated whelks may have been produced over at least a three-month period, but this contamination may have been intermittent, at a consistently low level. This would account for the relatively small number of cases seen.

We hope to be able to undertake whole genome sequencing of all outbreak cases and environmental isolates in future. Providing suitable background isolates are sequenced, this should allow a higher level of discrimination within the cases to ascertain which may be an artefact of sporadic incidence. Cases who did not report whelk consumption may have been sporadic or secondary cases. Regarding the case who was six months-old, one possible explanation is that the infant may have been infected by a family member who had eaten contaminated whelks, but who was asymptomatic.
Of the 38 cases, 10 were hospitalised, of whom four were admitted to intensive care. This level of severity has not previously been reported for Salmonella Goldcoast. Salmonella incidence is usually highest among the youngest (aged o to 4 years) [12]. As these cases had a median age of 65 years, they may have been more likely to have co-morbidities that increase the risk of hospitalisation.

One limitation of this study was that memory recall may have been different in case and control groups. To minimise this, cases and controls were interviewed in as timely a fashion as possible. Another limitation was that by using sequential digit dialling, a preponderance of females were recruited (20/27), whereas 25/38 of the cases were male. Explicit or frequency matching of controls was not possible due to the resources available for the investigation. To address this, sex was adjusted for in the analysis. It should also be noted that due to the small number of cases and controls, the $\mathrm{Cls}$ around the estimates of effect were wide.

We consider that the measures put in place to control this outbreak were effective in preventing further cases in England. Whelks are a novel vehicle of Salmonella infection and should be considered in the investigation of future outbreaks. It is known that processed whelks are sold internationally, and so if contaminated, there is the potential for cases to occur in countries outside the UK.

\section{Acknowledgements}

This article has been written on behalf of the Outbreak Control Team. With thanks to Anglia Health Protection Team administration and information staff for their work in the carrying out interviews for the case-control study, local Public Health England centres and Local Authorities for their assistance in the investigation of cases and Isabel Oliver, Richard Puleston and André Charlett for comments on the manuscript.

\section{Conflict of interest}

None declared.

Authors' contributions

All authors contributed to the writing of this manuscript and approved the final version.

TI designed the case-control study, analysed the data, drafted the manuscript and coordinated the outbreak response. GB organised data collection, food chain and environmental investigations. CL interpreted epidemiological and microbiological results. VH contributed to the environmental investigation. TP and KP were responsible for the microbiological results. RM coordinated the food chain investigation. GKA provided advice for the case-control study and the manuscript. AGS led and chaired the Outbreak Control Team, coordinated the outbreak response and advised on the manuscript. 


\section{References}

1. Hopkins KL, Peters TM, Lawson AJ, Owen RJ. Rapid identification of Salmonella enterica subsp. arizonae and S. enterica subsp. diarizonae by real-time polymerase chain reaction. Diagn Microbiol Infect Dis. 2009;64(4):452-4. http://dx.doi.org/10.1016/j.diagmicrobio.2009.03.022 PMid:19631101

2. Hopkins KL, Lawson AJ, Connell S, Peters TM, de Pinna E. A novel real-time polymerase chain reaction for identification of Salmonella enterica subspecies enterica. Diagn Microbiol Infect Dis. 2011;70(2):278-80.

http://dx.doi.org/10.1016/j.diagmicrobio.2011.01.015 PMid:21411262

3. Grimont PA, Weill FX. Antigenic formulae of the Salmonella serovars. 9th ed. Paris: World Health Organization Collaborating Centre for Reference and Research on Salmonella, Institut Pasteur; 2007. Available from: http:// www.pasteur.fr/ip/portal/action/WebdriveActionEvent/ oid/01s-000036-089

4. Scavia G, Ciaravino G, Luzzi I, Lenglet A, Ricci A, Barco L, et al. A multistate epidemic outbreak of Salmonella Goldcoast infection in humans, June 2009 to March 2010: the investigation in Italy. Euro Surveill. 2013;18(11):pii=20424. Available from: http://www.eurosurveillance.org/ViewArticle. aspx?Articleld $=20424$

5. Horváth JK, Mengel M, Krisztalovics K, Nogrady N, Pászti J, Lenglet A, et al. Investigation into an unusual increase of human cases of Salmonella Goldcoast infection in Hungary in 2009. Euro Surveill. 2013;18(11):pii=20422. Available from: http://www.eurosurveillance.org/ViewArticle. aspx?Articleld $=20422$

6. Threlfall EJ, Hall ML, Rowe B. Salmonella gold-coast from outbreaks of food-poisoning in the British Isles can be differentiated by plasmid profiles. J Hyg (Lond). 1986;97(1):11522.

http://dx.doi.org/10.1017/S0022172400064408

7. Bremer V, Leitmeyer K, Jensen E, Metzel U, Meczulat H, Weise E, et al. Outbreak of Salmonella Goldcoast infections linked to consumption of fermented sausage, Germany 2001. Epidemiol Infect. 2004;132(5):881-7.

http://dx.doi.org/10.1017/S0950268804002699 PMid:15473151 PMCid:PMC2870175

8. Joce R, O'Sullivan DG, Strong C, Rowe B, Hall ML, Threlfall EJ. A national outbreak of Salmonella Gold-coast. Commun Dis Rep CDR Rev. 1990;4:3-4.

9. Salmonella Gold-coast and cheddar cheese: update. Commun Dis Rep CDR Wkly. 1997;7(11):93, 96.

10. Reid TM, Gould IM, Mackie IM, Ritchie AH, Hobbs G. Food poisoning due to the consumption of red whelks (Neptunea antiqua). Epidemiol Infect. 1988;101(2): 419-23 http://dx.doi.org/10.1017/S0950268800054376 PMid:3181322 PMCid:PMC2249389

11. Martinez-Urtaza J, Peiteado J, Lozano-León A, Garcia-Martin 0 . Detection of Salmonella Senftenberg associated with high saline environments in mussel processing facilities. J Food Prot. 2004;67(2):256-63. PMid:14968956

12. Health Protection Agency (HPA). Epidemiology of Salmonella infections in London, 2007-2011. 4 January 2013. London: HPA; 2013. Available from: http://www.hpa.org.uk/webc/ HPAwebFile/HPAweb_C/1317138078463 